\title{
A Study on Incidence of Communicating branch between Musculocutaneous Nerve and Median Nerve
}

\section{T Naveen Sagar *1, M Venkata Raga Mayuri ${ }^{2}$, Anshu Sharma ${ }^{3}$, Rajat Subhra Das ${ }^{4}$.}

${ }^{{ }_{1}}$ Assistant Professor, Department of Anatomy, All India Institute of Medical Sciences, Raebareli, Uttar Pradesh, India.

${ }^{2}$ Assistant Professor, Department of Anatomy, Meenakshi Medical college, Kanchipuram, Tamil Nadu, India.

${ }^{3}$ Professor and Head, Department of Anatomy, All India Institute of Medical Sciences, Raebareli, Uttar Pradesh, India.

${ }^{4}$ Additional Professor, Department of Anatomy, All India Institute of Medical Sciences, Raebareli, Uttar Pradesh, India.

\section{ABSTRACT}

Introduction: In present day Surgical practice it is mandatory to have a detailed idea of basic Anatomy and possible variations from normal pattern of all the major nerves and vessels in the body. One such important nerve in the body is Musculo Cutaneous nerve which is the chief nerve supplying the muscles of the front of the arm and also supplies the skin of lateral aspect of forearm. In the present study undertaken 58 upperlimbs were dissected and the incidence of communicating branch between Musculocutaneous Nerve and Median Nerve was studied.

Aims and Objectives: The study is undertaken to know the incidence of communicating branch between Musculocutaneous Nerve and Median Nerve and its importance in surgical approaches of the upper limb.

Materials and Methods: Under aseptic precautions, Standard dissection procedures were followed to dissect out the Musculocutaneous nerves and Median nerves in the 58 upper limbs of both right and left sides in the human cadavers of both sexes and the incidence of communicating branch between Musculocutaneous Nerve and Median Nerve were studied in detail and images were taken with digital camera for proper presentation of the study.

Results and Conclusion: In the present study undertaken 7 upper limbs (12 percent) out of 58 upper limbs dissected showed the presence of communicating branch between Musculocutaneous nerve and Median nerve which comes under the category of type II of choi et al classification. on an average percentage of incidence of communicating branch between Musculocutaneous nerve and Median nerve varies between 10 percent to 53 percent.

KEY WORDS: Musculocutaneous nerve, Median nerve and communication between Musculocutaneous nerve and median nerve.

Corresponding Author: Dr T Naveen Sagar, Assistant Professor, Department of Anatomy, All India Institute of Medical Sciences, Raebareli, Uttar Pradesh, India.

Phone: 8106701848, 9573084236. E-Mail: tnsdsmbbs@gmail.com.

\begin{tabular}{|c|c|c|c|}
\hline Access this Article online & \multicolumn{3}{|c|}{ Journal Information } \\
\hline \multirow[t]{3}{*}{ Quick Response code } & \multicolumn{3}{|c|}{$\begin{array}{l}\text { International Journal of Anatomy and Research } \\
\text { ISSN (E) 2321-4287 | ISSN (P) 2321-8967 } \\
\text { https://www.ijmhr.org/ijar.htm } \\
\text { DOI-Prefix: https://dx.doi.org/10.16965/ijar }\end{array}$} \\
\hline & \multicolumn{3}{|c|}{ Article Information } \\
\hline & $\begin{array}{l}\text { Received: 07 Feb } 2021 \\
\text { Peer Review: 08 Feb } 2021 \\
\text { Revised: None }\end{array}$ & $\begin{array}{l}\text { Accepted: } 15 \text { Mar } \\
\text { Published (O): } 15 \\
\text { Published (P): } 05\end{array}$ & $\begin{array}{l}21 \\
2021 \\
2021\end{array}$ \\
\hline
\end{tabular}

\section{INTRODUCTION}

In present day Surgical practice it is mandatory to have a detailed idea of basic Anatomy and possible variations from normal pattern of all the major nerves and vessels in the body. One such important nerve in the body is 
Musculo Cutaneous nerve which is the chief nerve supplying the muscles of the front of the arm and also supplies the skin of lateral aspect of forearm. In the present study undertaken 58 upperlimbs were dissected and the incidence of communicating branch between Musculocutaneous Nerve and Median Nerve was studied. Abnormal communication between median nerve and musculo cutaneous nerve have been commonly observed and classified into different sub types by many researchers. The present study undertaken is targeted at finding the presence of such abnormal communication between the median nerve and musculocutaneous nerve and its clinical importance.

\section{Aims and Objectives:}

Aim: Aim of the study is to study the incidence of communicating branch between Musculocutaneous Nerve and Median Nerve in 58 upper limbs of both right and left sides in human cadavers of both sexes.

Objective: The objective of the study is to know the incidence of communicating branch between Musculocutaneous Nerve and Median Nerve and its importance in surgical approaches of the upper limb.

\section{MATERIALS AND METHODS}

Materials: In the present study all the upper limbs used for the study were obtained from the Department of Anatomy, Apollo Institute of Medical Sciences and Research, Murukambattu, Chittoor, Andhra Pradesh. The materials used are as follows: Dissection knife, Toothed forceps, Blunt forceps, Pointed forceps, Scissors, needles, Cotton. A high resolution digital camera was used for obtaining high quality images. A computer was used for better presentation and editing of the study.

Methods: Under aseptic precautions, Standard dissection procedures were followed to dissect out the Musculocutaneous nerves and Median nerves in the 58 upper limbs of both right and left sides in the human cadavers of both sexes and the incidence of communicating branch between Musculocutaneous Nerve and Median Nerve were studied in detail and images were taken with digital camera for proper presentation of the study.

\section{OBSERVATIONS AND RESULTS}

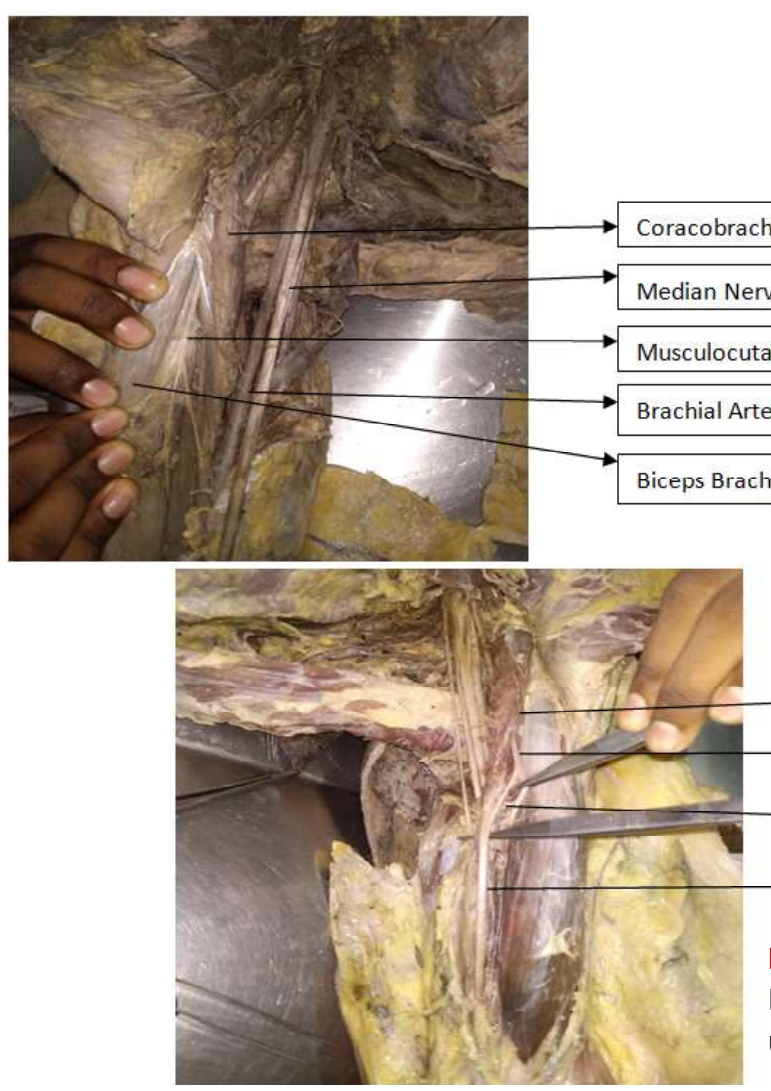

Fig. 1: Showing Normal course and branching pattern of Musculocutaneous Nerve. 


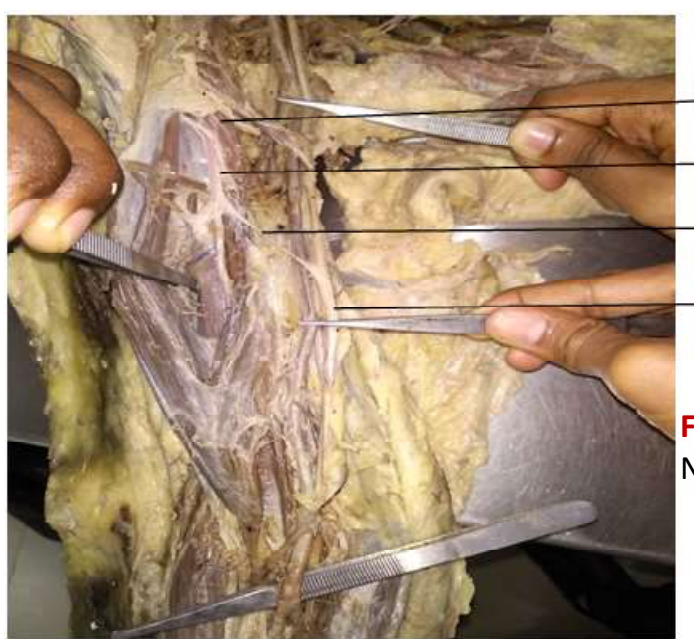

In the present study undertaken 58 upper limb specimens were dissected and musculocutaneous nerves were studied. 7 upper limbs showed abnormal communication between musculocutaneous nerve and median nerve, out of the 7 upper limbs 4 were right upper limbs and 3 were left upper limbs figure 1 shows the normal course and branching pattern of the musculocutaneous nerve. The communication in all the 7 upper limbs was distal to the passage of musculocutaneous nerve through the coracobrachialis muscle. Figure 2 shows the communicating branch between musculocutaneous nerve and median nerve in left upper limb. Figure 3 shows thecommunication between musculocutaneous nerve and median nerve in right upperlimb. In present study 12 percent of the upper extremities i.e 7 upper limbs out of 58 upper extremities shows abnormal communication between musculocutaneous nerve and median nerve. Rest of the 51 upper limbs showed the normal course and branching pattern of the musculocutaneous nerve.

\section{DISCUSSION}

Many researchers classified the communication between Musculocutaneous nerve and Median nerve in to different types. Among such classifications one classification which suits the present study is taken into consideration, Choi et al. [1] classified the communications between the musculocutaneous nerve and the median nerve into three types. In Type I the musculocutaneous nerve and median nerve were fused, In Type II one connecting branch between the musculocutaneous nerve and median nerve and In Type III two connecting branches were present between musculocutaneous nerve and median nerve. In present study there was one connecting branch between musculocutaneous nerve and median nerve in 7 upper limbs, this communication falls under type II of Choi et al classification. According to Edie Benedito Caetano and Luiz Angelo Vieira et al [2] out of 40 upper extremities of fetuses dissected 10 upper extremities showed communication between Musculocutaneous nerve and Median nerve out of which in 9 upper limbs communicating branches were going from musculo cutaneous nerve to median nerve and in one upper limb communicating branch was going from median nerve to musculo cutaneous nerve. In the present study, in all 7 upper limbs the communicating branche was going from musculocutaneous nerve to median nerve distal to the passage of musculocutaneous nerve through the coracobrachialis muscle. According to Kervancioglu, Orhan M, Kilinc N [3] out of 20 upper limbs dissected from fetuses, 5 upper limbs showed communication between Musculocutaneous nerve and Median nerve. According to Uysal , Karabulut AK, Buyukmumcu M, Unver Dogan N, Salbacak A, [4] out of 140 fetal arms 10 percent showed communication between Musculocutaneous nerve and Median nerve, in the present study undertaken out of 58 upper limbs 12 percent showed the presence of communicating branch between Musculocutaneous nerve and Median nerve. According to Guerri-Guttenberg, R.A and Ingolotti, [5] out of 56 upper limbs dissected from both fetuses and adult 53.6 percent of the dissections showed communication between Musculocutaneous nerve and Median nerve, among 
T Naveen Sagar, et al., A Study on Incidence of Communicating branch between Musculocutaneous Nerve and Median Nerve.

these communication 84 percent were proximal, 7.7 percent were distal and in 7.7 percent one proximal and one distal communication were present.

According to Kwolczak-McGrath A, Kolesnik A, Ciszek B, [6] out of 40 upper limbs dissected from fetuses, 20 percent showed the presence of communication between Musculocutaneous nerve and Median nerve. According to Venieratos D, Anagnostopoulou S [7] out of 79 cadavers dissected 16 (20 percent) cadavers had communication between Musculocutaneous nerve and Median nerve in 6 cadavers the communication was bilateral. Total of 22 communication branches were present out of which 9 were type I (communicating branch was proximal to the passage of Musculocutaneous nerve through Coracobrachialis), 10 were type II (communicating branch was distal to the passage of Musculocutaneous nerve through Coracobrachialis), 3 were type 3 (Musculocutaneous nerve and communicating branch does not pass through the Coracobrachialis muscle). In present study undertaken all the 7 communicating branches were of type II (communicating branch was distal to the passage of Musculocutaneous nerve through Coracobrachialis).
According to Choi D, Rodriguez-Niedenfuhr M, Vazquez T, Parkin I, Sanudo JR [1] out of 138 cadavers in which study was done 64 cadavers showed communication between Musculocutaneous nerve and Median nerve (55 cadavers unilateral and 9 cadavers bilateral). These variations were categorized into three types, type I fusion of both nerves was seen in 14 upper limbs (19.2\%), type II, presence of one communicating branch between both nerves was seen in 53 upper limbs (72.6\%); and type III, two communicating branches between both nerves was seen in 5 upperlimbs, (6.8\%). According to Sonali Abhijeet Khake, Dinit K Tom, Swati Milind Belsare [8] out of 60 upper limb specimens studied 21 (36.6 percent) upper limbs showed the presence of communication between Musculocutaneous nerve and the Median nerve. Like this many researchers have contributed in identifying the incidence of communication between Musculocutaneous nerve and the Median nerve and also further classified the communication in to different sub types.

Table 1: Showing Incidence of communicating branch between Musculocutaneous nerve and Median nerve.

\begin{tabular}{ll}
\hline \multicolumn{1}{c|}{ Author Year } & $\begin{array}{l}\text { Percentage of Incidence of communicating } \\
\text { branch between Musculocutaneous Nerve and } \\
\text { Median Nerve }\end{array}$ \\
\hline Edie Benedito Caetano and Luiz Angelo Vieira et al 2016 [2] & 25 percent \\
\hline Kervancioglu, Orhan M, Kilinc N 2011 [3] & 25 percent \\
\hline Uysal , Karabulut AK, Buyukmumcu M, Unver Dogan N, Salbacak A 2009 [4] & 10 percent \\
Guerri-Guttenberg, R.A and Ingolotti 2009 [5] & 53.6 percent \\
\hline Kwolczak-McGrath A, Kolesnik A, Ciszek B 2008 [6] & 20 percent \\
\hline Venieratos D, Anagnostopoulou S 1998 [7] & 20 percent \\
\hline Choi D, Rodriguez-Niedenfuhr M, Vazquez T, Parkin I, Sanudo JR 2002 [1] & 46.3 percent \\
Sonali Abhijeet Khake, Dinit K Tom, Swati Milind Belsare 2018 [8] & 36.66 \\
\hline Present study 2019 & 12 percent \\
\hline
\end{tabular}

Table 2: Classification according to Choi et al [1].

\begin{tabular}{lccc}
\hline \multicolumn{1}{c}{ Author } & Type I & Type II & Type III \\
\hline Choi D, Rodriguez-Niedenfuhr M, Vazquez & 19.2 percent & 72.6 percent & 6.8 percent \\
T, Parkin I, Sanudo JR 2002 [1] & Nil & 12 percent & Nil \\
\hline Present study 2019 & &
\end{tabular}

Type I the Musculocutaneous nerve and Median nerve were fused.

Type II one connecting branch between the Musculocutaneous nerve and Median nerve

Type III two connecting branches were present between Musculocutaneous nerve and Median nerve 


\section{CONCLUSION}

In the present study undertaken 7 upper limbs (12 percent) out of 58 upper limbs dissected showed the presence of communicating branch between Musculocutaneous nerve and Median nerve which comes under the category of type II of choi et al (1) classification. on an average percentage of incidence of communicating branch between Musculocutaneous nerve and Median nerve varies between 10 percent to 53 percent. In routine surgical practice orthopedicians and neurosurgeons who are regularly practicing surgeries of the upper limbs it is essential to know the detailed knowledge of possible variations of these nerves and their surgical importance to provide better outcome to the patient.

\section{ACKNOWLEDGEMENTS}

I thank Dr Rachel Koshi Head of the department, department of Anatomy, Apollo Institute of Medical Sciences and Research, Chittoor, Andhra Pradesh. I also thank all the department staff for their support.

\section{Conflicts of Interests: None}

\section{REFERENCES}

[1]. Choi D, Rodríguez-Niedenführ M, Vázquez T, Parkin I, Sañudo JR Patterns of connections between the musculocutaneous and median nerves in the axilla and arm. Clin Anat. 2002 Jan;15(1):11-7.

[2]. Edie Benedito Caetano, Luiz Ângelo Vieira, Cristina Schmitt Cavalheiro, Mauro Razuk, Filho, Marco Antonio Pires Almargo, and Mauricio Ferreira Caetano Anatomic Study Of The Nervous Communication Between The Median And Musculoucutaneous Nerve Acta Ortop Bras. 2016 Jul-Aug; 24(4): 200-203. doi: 10.1590/1413785220162404159372

[3]. Kervancioglu P, Orhan M, Kilinc N. Patterns of motor branching of the musculocutaneous nerve in human fetuses and clinical significance. Clin Anat. 2011 Mar;24(2):168-78. doi: 10.1002/ ca.21095. Epub 2011 Jan 25.

[4]. Uysal II, Karabulut AK, Büyükmumcu M, Unver Dogan N, Salbacak A. The course and variations of the branches of the musculocutaneous nerve in human fetuses. Clin Anat. 2009 Apr;22(3):337-45. doi: 10.1002/ca.20734

[5]. Guerri-Guttenberg, R.A., Ingolotti, M. Classifying musculocutaneous nerve variations Clinical AnatomyVolume 22, Issue 6, September 2009, Pages 671-683

[6]. Kwolczak-McGrath A, Kolesnik A, Ciszek B.Anatomy of branches of the musculocutaneous nerve to the biceps and brachialis in human fetuses. Clin Anat. 2008 Mar;21(2):142-6. doi: 10.1002/ ca.20583.

[7]. Venieratos D, Anagnostopoulou S. Classification of communications between the musculocutaneous and median nerves. Clin Anat. 1998;11(5):327-31.

[8]. Khake SA, Tom DK, Belsare SM. Variations in branching pattern of musculocutaneous nerve with respect to communicating branch between musculocutaneous and median nerve. Int J Anat Var. 2018;11(3):77-80.

[9]. Sachdeva, K., Singla, K.K Communication between median and musculocutaneous nerve Journal of Morphological Sciences. 2011;28(4):246-249.

[10]. Oztürk NC, Uzmansel D, Oztürk H. An unreported pattern of musculocutaneous and median nerve communication with multiple variations of biceps brachii: a case report. Surg Radiol Anat. 2010 Nov;32(9):887-90. doi: 10.1007/s00276-0090616-6. Epub 2010 Jan 5.

[11]. Le Minor JM A rare variation of the median and musculocutaneous nerves in man. Arch Anat Histol Embryol. 1990;73:33-42.

[12]. Chentanez V, Jaruprat P, Udomchaisakul P, Agthong $S$, Huanmanop T. Multiple variations in the course and motor branching pattern of the musculocutaneous nerve with unusual communication with the median nerve. Folia Morphol (Warsz). 2016;75(4):555-559. doi: 10.5603/ FM.a2016.0014. Epub 2016 Nov 10.

[13]. Eglseder WA Jr, Goldman M. Anatomic variations of the musculocutaneous nerve in the arm. Am J Orthop (Belle Mead NJ). 1997 Nov;26(11):777-80.

[14]. Basar R, Aldur MM, Celik HH, Yüksel M, Tasçioglu AB. A connecting branch between the musculocutaneous nerve and the median nerve. Morphologie. 2000 Sep;84(266):25-7

[15]. Prasada Rao PV, Chaudhary SC. Communication of the musculocutaneous nerve with the median nerve. East Afr Med J. 2000 Sep;77(9):498-503.

[16]. Hayashi M, Shionoya K, Hayashi S, Hatayama N, Kawata S, Qu N, Hirai S, Miyaso H, Itoh M. A novel classification of musculocutaneous nerve variations: The relationship between the communicating branch and transposed innervation of the brachial flexors to the median nerve. Ann Anat. 2017 Jan;209:45-50. doi: 10.1016/ j.aanat.2016.08.004. Epub 2016 Oct 17

[17]. Parchand MP, Patil ST. Absence of musculocutaneous nerve with variations in course and distribution of the median nerve. Anat Sci Int. 2013 Jan;88(1):58-60. doi: 10.1007/s12565-011-01266. Epub 2012 Jan 12.

[18]. Nasrabadi HT, Abedelahi A, Shoorei H, Shokoohi M, Salimnejad R, Dolatkhah MA, Seghinsara AM. A variation of Musculocutaneous nerve without piercing the coracobrachialis muscle while communicating to the median nerve: A case report and literature review. Int J Surg Case Rep. 2017 Nov 15;41:453-455. doi: 10.1016/j.ijscr.2017.11.020. eCollection 2017. 
T Naveen Sagar, et al., A Study on Incidence of Communicating branch between Musculocutaneous Nerve and Median Nerve.

[19]. Beheiry EE. Anatomical variations of the median nerve distribution and communication in the arm. Folia Morphol (Warsz). 2004 Aug;63(3):313-8.

[20]. Nakatani T, Mizukami S, Tanaka S. Three cases of the musculocutaneous nerve not perforating the coracobrachialis muscle. Kaibogaku Zasshi. 1997 Jun;72(3):191-4
[21]. Bhattarai C, Poudel PP. Unusual variation in musculocutaneous nerves in Nepalese. Kathmandu Univ Med J (KUMJ). 2009 Oct-Dec;7(28):408-10.

How to cite this article:

T Naveen Sagar, M Venkata Raga Mayuri, Anshu Sharma, Rajat Subhra Das. A Study on Incidence of Communicating branch between Musculocutaneous Nerve and Median Nerve. Int J Anat Res 2021;9(2.1):7936-7941. DOI: 10.16965/ijar.2021.112 